\title{
Strong convergence of some iterative algorithms for a general system of variational inequalities
}

\author{
Jong Soo Jung
}

Department of Mathematics, Dong-A University, Busan 49315, Korea.

Communicated by M. Eslamian

\begin{abstract}
In this paper, we introduce two iterative algorithms (one implicit algorithm and one explicit algorithm) for finding a common element of the solution set of a general system of variational inequalities for continuous monotone mappings and the fixed point set of a continuous pseudocontractive mapping in a Hilbert space. First, this system of variational inequalities is proven to be equivalent to a fixed point problem of nonexpansive mapping. Then we establish strong convergence of the sequence generated by the proposed iterative algorithms to a common element of the solution set and the fixed point set, which is the unique solution of a certain variational inequality. (C)2017 All rights reserved.
\end{abstract}

Keywords: Composite iterative algorithm, general system of variational inequatlites, continuous monotone mapping, continuous peudocontractive mapping, $\rho$-Lipschitzian, $\eta$-strongly monotone mapping, variational inequality, strongly positive bounded linear operator, fixed points.

2010 MSC: 47J20, 47H05, 47H09, 47H10, 49J40, 49M05.

\section{Introduction}

Let $\mathrm{H}$ be a real Hilbert space with inner product $\langle\cdot, \cdot\rangle$ and induced norm $\|\cdot\|$. Let $\mathrm{C}$ be a nonempty closed convex subset of $\mathrm{H}$ and let $\mathrm{S}: \mathrm{C} \rightarrow \mathrm{C}$ be a self-mapping on $\mathrm{C}$. We denote by Fix $(\mathrm{S})$ the set of fixed points of $S$.

A mapping $\mathrm{F}: \mathrm{C} \rightarrow \mathrm{H}$ is called monotone, if

$$
\langle x-y, F x-F y\rangle \geqslant 0, \quad \forall x, y \in C,
$$

and $F$ is called $\alpha$-inverse-strongly monotone (see $[5,10])$ if there exists a positive real number $\alpha$ such that

$$
\langle x-y, F x-F y\rangle \geqslant \alpha\|F x-F y\|^{2}, \quad \forall x, y \in C .
$$

The class of monotone mappings includes the class of $\alpha$-inverse-strongly monotone mappings.

A mapping $\mathrm{T}: \mathrm{C} \rightarrow \mathrm{H}$ is said to be pseudocontractive, if

$$
\|\mathrm{T} x-\mathrm{T} y\|^{2} \leqslant\|x-y\|^{2}+\|(\mathrm{I}-\mathrm{T}) x-(\mathrm{I}-\mathrm{T}) \mathrm{y}\|^{2}, \quad \forall x, y \in \mathrm{C},
$$

Email address: jungjs@dau.ac.kr (Jong Soo Jung)

doi:10.22436/jnsa.010.07.42 
and $T$ is said to be $k$-strictly pseudocontractive, if there exists a constant $k \in[0,1)$ such that

$$
\|T x-T y\|^{2} \leqslant\|x-y\|^{2}+k\|(I-T) x-(I-T) y\|^{2}, \quad \forall x, y \in C,
$$

where I is the identity mapping. Note that the class of k-strictly pseudocontractive mappings includes the class of nonexpansive mappings as a subclass. That is, $T$ is nonexpansive (i.e., $\|T x-T y\| \leqslant\|x-y\|$, for all $x, y \in C$ ) if and only if $T$ is 0 -strictly pseudocontractive. Clearly, the class of pseudocontractive mappings includes the class of strictly pseudocontractive mappings as a subclass.

Let $\mathrm{F}$ be a nonlinear mapping of $\mathrm{C}$ into $\mathrm{H}$. The variational inequality problem (VIP) is to find a $x^{*} \in \mathrm{C}$ such that

$$
\left\langle\mathrm{F} x^{*}, x-x^{*}\right\rangle \geqslant 0, \quad \forall x \in C .
$$

We denote the set of solutions of VIP (1.1) by VI(C,F). The variational inequality problem has been extensively studied in the literature; see $[3,5,7,9,10,13,14,16,18]$ and the references therein.

In 2008, Ceng et al. [2] considered the following general system of variational inequalities:

$$
\begin{cases}\left\langle\lambda F_{1} y^{*}+x^{*}-y^{*}, x-x^{*}\right\rangle \geqslant 0, & \forall x \in C, \\ \left\langle v F_{2} x^{*}+y^{*}-x^{*}, x-y^{*}\right\rangle \geqslant 0, & \forall x \in C,\end{cases}
$$

where $F_{1}$ and $F_{2}$ are an $\alpha$-inverse-strongly monotone mapping and a $\beta$-inverse-strongly monotone mapping, respectively, and $\lambda \in(0,2 \alpha)$ and $v \in(0,2 \beta)$ are two constants. For finding an element Fix $(S) \cap \Gamma$, where $S: C \rightarrow C$ is a nonexpansive mapping and $\Gamma$ is the solution set of the problem (1.2), they introduced a relaxed extragradient method ([8]) and proved strong convergence to a common element of Fix (S) $\cap \Gamma$.

In 2016, Alofi et al. [1] also considered the problem (1.2) coupled with the fixed point problem, and introduced two composite iterative algorithms (one implicit algorithm and one explicit algorithm) based on Jung's composite iterative method [6] to find an element Fix $(T) \cap \Gamma$, where $T: C \rightarrow C$ is a k-strictly pseudocontractive mapping and $\Gamma$ is the solution set of the problem (1.2), and showed strong convergence to a common element of $F i x(T) \cap \Gamma$. The following problems arise:

Question 1. Can we extend the class of inverse-strongly monotone mappings in $[1,2]$ to the more general class of continuous monotone mappings?

Question 2. Can we extend the class of nonexpansive mappings in [2] or the class of strictly pseudocontractive mappings in [1] to the more general class of pseudocontractive mappings?

In this paper, in order to give the affirmative answers to the above two questions, we consider a general system of variational inequalities slightly different from the problem (1.2). More precisely, we introduce the following general system of variational inequalities (GSVI) for two continuous monotone mappings $F_{1}$ and $F_{2}$ of finding $\left(x^{*}, y^{*}\right) \in C \times C$ such that

$$
\begin{cases}\left\langle\lambda \mathrm{F}_{1} x^{*}+x^{*}-y^{*}, x-x^{*}\right\rangle \geqslant 0, & \forall x \in C, \\ \left\langle v F_{2} y^{*}+y^{*}-x^{*}, x-y^{*}\right\rangle \geqslant 0, & \forall x \in C,\end{cases}
$$

where $\lambda>0$ and $v$ are two constants. The solution set of GSVI (1.3) is denoted by $\Omega$. First, we prove that the problem (1.3) is equivalent to a fixed point problem of nonexpansive mapping. Second, by using Jung's composite iterative algorithms [6], we introduce a composite implicit iterative algorithm and a composite explicit iterative algorithm for finding a common element of $\Omega \cap$ Fix $(T)$, where T is a continuous pseudocontractive mapping. Then we establish strong convergence of these two composite iterative algorithms to a common element of $\Omega \cap$ Fix $(T)$, which is the unique solution of a certain variational inequality related to a minimization problem. As a direct consequence, we obtain strong convergence to a common element of $\mathrm{VI}(\mathrm{C}, \mathrm{F}) \cap \mathrm{Fix}(\mathrm{T})$, where $\mathrm{F}$ is a continuous monotone mapping.

\section{Preliminaries and lemmas}

Let $\mathrm{H}$ be a real Hilbert space and let $\mathrm{C}$ be a nonempty closed convex subset of $\mathrm{H}$. We write $x_{n} \rightarrow x$ to indicate that the sequence $\left\{x_{n}\right\}$ converges weakly to $x . x_{n} \rightarrow x$ implies that $\left\{x_{n}\right\}$ converges strongly to $x$. 
For every point $x \in H$, there exists a unique nearest point in $C$, denoted by $P_{C}(x)$, such that

$$
\left\|x-P_{C}(x)\right\| \leqslant\|x-y\|, \quad \forall y \in C .
$$

$\mathrm{P}_{\mathrm{C}}$ is called the metric projection of $\mathrm{H}$ onto $\mathrm{C}$. It is well-known that $\mathrm{P}_{\mathrm{C}}(\mathrm{x})$ is characterized by the property:

$$
u=P_{C}(x) \Longleftrightarrow\langle x-u, u-y\rangle \geqslant 0, \quad \forall x \in H, y \in C .
$$

In a Hilbert space $\mathrm{H}$, we have

$$
\|x-y\|^{2}=\|x\|^{2}+\|y\|^{2}-2\langle x, y\rangle, \quad \forall x, y \in H .
$$

We recall that:

(i) an operator $A$ is said to be strongly positive on $H$, if there exists a constant $\bar{\gamma}>0$ such that

$$
\langle A x, x\rangle \geqslant \bar{\gamma}\|x\|^{2}, \quad \forall x \in H ;
$$

(ii) a mapping $\mathrm{V}: \mathrm{C} \rightarrow \mathrm{H}$ is said to be l-Lipschitzian, if there exists a constant $\mathrm{l} \geqslant 0$ such that

$$
\|V x-V y\| \leqslant l\|x-y\|, \quad \forall x, y \in C ;
$$

(iii) a mapping $\mathrm{G}: \mathrm{C} \rightarrow \mathrm{H}$ is said to be $\rho$-strongly monotone, if there exists a constant $\rho>0$ such that

$$
\langle G x-G y, x-y\rangle \geqslant \rho\|x-y\|^{2}, \quad \forall x, y \in C .
$$

The following lemma is an immediate consequence of an inner product.

Lemma 2.1. In a real Hilbert space $\mathrm{H}$, there holds the following inequality

$$
\|x+y\|^{2} \leqslant\|x\|^{2}+2\langle y, x+y\rangle, \quad \forall x, y \in H .
$$

We need the following lemmas for the proof of our main results.

Lemma 2.2 ([15]). Let $\left\{\mathrm{s}_{\mathrm{n}}\right\}$ be a sequence of non-negative real numbers satisfying

$$
s_{n+1} \leqslant\left(1-\omega_{n}\right) s_{n}+\omega_{n} \delta_{n}+v_{n}, \quad \forall n \geqslant 1,
$$

where $\left\{\omega_{n}\right\},\left\{\delta_{n}\right\}$, and $\left\{v_{n}\right\}$ satisfy the following conditions:

(i) $\left\{\omega_{n}\right\} \subset[0,1]$ and $\sum_{n=1}^{\infty} \omega_{n}=\infty$ or, equivalently, $\prod_{n=1}^{\infty}\left(1-\omega_{n}\right)=0$;

(ii) $\limsup _{n \rightarrow \infty} \delta_{n} \leqslant 0$ or $\sum_{n=1}^{\infty} \omega_{n}\left|\delta_{n}\right|<\infty$;

(iii) $v_{n} \geqslant 0(n \geqslant 1), \sum_{n=1}^{\infty} v_{n}<\infty$.

Then $\lim _{n \rightarrow \infty} s_{n}=0$.

Lemma 2.3 (Demiclosedness principle [4]). Let $\mathrm{C}$ be a nonempty closed convex subset of a real Hilbert space $\mathrm{H}$, and let $\mathrm{S}: \mathrm{C} \rightarrow \mathrm{C}$ be a nonexpansive mapping. Then, the mapping $\mathrm{I}-\mathrm{S}$ is demiclosed. That is, if $\left\{\mathrm{x}_{\mathrm{n}}\right\}$ is a sequence in $\mathrm{C}$ such that $\mathrm{x}_{\mathrm{n}} \rightarrow \mathrm{x}^{*}$ and $(\mathrm{I}-\mathrm{S}) \mathrm{x}_{\mathrm{n}} \rightarrow \mathrm{y}$, then $(\mathrm{I}-\mathrm{S}) \mathrm{x}^{*}=\mathrm{y}$.

Lemma 2.4 ([11]). Let $\mathrm{H}$ be a real Hilbert space. Let $\mathrm{A}: \mathrm{H} \rightarrow \mathrm{H}$ be a strongly positive bounded linear operator with a constant $\bar{\gamma}>1$. Then

$$
\langle(A-I) x-(A-I) y, x-y\rangle \geqslant(\bar{\gamma}-1)\|x-y\|^{2}, \quad \forall x, y \in C .
$$

That is, A $-\mathrm{I}$ is strongly monotone with a constant $\bar{\gamma}-1$. 
Lemma 2.5 ([11]). Assume that $\mathrm{A}$ is a strongly positive bounded linear operator on $\mathrm{H}$ with a coefficient $\bar{\gamma}>0$ and $0<\zeta \leqslant\|A\|^{-1}$. Then $\|\mathrm{I}-\zeta \mathrm{A}\| \leqslant 1-\zeta \bar{\gamma}$.

The following lemma can be easily proven, and therefore, we omit the proof. (see [16]).

Lemma 2.6. Let $\mathrm{H}$ be a real Hilbert space. Let $\mathrm{G}: \mathrm{H} \rightarrow \mathrm{H}$ be a $\rho$-Lipschitzian and $\eta$-strongly monotone mapping with constants $\rho, \eta>0$. Let $0<\mu<\frac{2 \eta}{\rho^{2}}$ and $0<\mathrm{t}<\sigma \leqslant 1$. Then $\mathrm{S}:=\sigma \mathrm{I}-\mathrm{t} \mu \mathrm{G}: \mathrm{H} \rightarrow \mathrm{H}$ is a contractive mapping with constant $\sigma-\mathrm{t} \tau$, where $\tau=1-\sqrt{1-\mu\left(2 \eta-\mu \rho^{2}\right)}$.

The following lemmas are Lemma 2.3 and Lemma 2.4 of Zegeye [17], respectively.

Lemma 2.7 ([17]). Let $\mathrm{C}$ be a closed convex subset of a real Hilbert space $\mathrm{H}$. Let $\mathrm{F}: \mathrm{C} \rightarrow \mathrm{H}$ be a continuous monotone mapping. Then, for $\mathrm{r}>0$ and $\mathrm{x} \in \mathrm{H}$, there exists $z \in \mathrm{C}$ such that

$$
\langle y-z, F z\rangle+\frac{1}{r}\langle y-z, z-x\rangle \geqslant 0, \quad \forall y \in C .
$$

For $\mathrm{r}>0$ and $\mathrm{x} \in \mathrm{H}$, define $\mathrm{F}_{\mathrm{r}}: \mathrm{H} \rightarrow \mathrm{C}$ by

$$
\mathrm{F}_{\mathrm{r}} x=\left\{z \in \mathrm{C}:\langle\mathrm{y}-z, \mathrm{~F} z\rangle+\frac{1}{\mathrm{r}}\langle\mathrm{y}-z, z-x\rangle \geqslant 0, \quad \forall \mathrm{y} \in \mathrm{C}\right\}
$$

Then the following hold:

(i) $\mathrm{F}_{\mathrm{r}}$ is single-valued;

(ii) $\mathrm{F}_{\mathrm{r}}$ is firmly nonexpansive, that is,

$$
\left\|F_{r} x-F_{r} y\right\|^{2} \leqslant\left\langle x-y, F_{r} x-F_{r} y\right\rangle, \quad \forall x, y \in H ;
$$

(iii) $\operatorname{Fix}\left(\mathrm{F}_{\mathrm{r}}\right)=\mathrm{VI}(\mathrm{C}, \mathrm{F})$;

(iv) $\operatorname{VI}(\mathrm{C}, \mathrm{F})$ is a closed convex subset of $\mathrm{C}$.

Lemma 2.8 ([17]). Let $\mathrm{C}$ be a closed convex subset of a real Hilbert space $\mathrm{H}$. Let $\mathrm{T}: \mathrm{C} \rightarrow \mathrm{H}$ be a continuous pseudocontractive mapping. Then, for $\mathrm{r}>0$ and $\mathrm{x} \in \mathrm{H}$, there exists $z \in \mathrm{C}$ such that

$$
\langle y-z, T z\rangle-\frac{1}{r}\langle y-z,(1+r) z-x\rangle \leqslant 0, \quad \forall y \in C .
$$

For $\mathrm{r}>0$ and $\mathrm{x} \in \mathrm{H}$, define $\mathrm{T}_{\mathrm{r}}: \mathrm{H} \rightarrow \mathrm{C}$ by

$$
\mathrm{T}_{\mathrm{r}} x=\left\{z \in \mathrm{C}:\langle\mathrm{y}-z, \mathrm{~T} z\rangle-\frac{1}{\mathrm{r}}\langle\mathrm{y}-z,(1+\mathrm{r}) z-x\rangle \leqslant 0, \quad \forall \mathrm{y} \in \mathrm{C}\right\} .
$$

Then the following hold:

(i) $\mathrm{T}_{\mathrm{r}}$ is single-valued;

(ii) $T_{r}$ is firmly nonexpansive, that is,

$$
\left\|T_{r} x-T_{r} y\right\|^{2} \leqslant\left\langle x-y, T_{r} x-T_{r} y\right\rangle, \quad \forall x, y \in H ;
$$

(iii) $\operatorname{Fix}\left(\mathrm{T}_{\mathrm{r}}\right)=\operatorname{Fix}(\mathrm{T})$;

(iv) Fix $(\mathrm{T})$ is a closed convex subset of $\mathrm{C}$.

\section{Main results}

Throughout the rest of this paper, we always assume the following:

- $\mathrm{H}$ is a real Hilbert space;

- $\mathrm{C}$ is a nonempty closed subspace of $\mathrm{H}$;

- $\mathrm{A}: \mathrm{C} \rightarrow \mathrm{C}$ is a strongly positive linear bounded self-adjoint operator with a constant $\bar{\gamma} \in(1,2)$;

- $\mathrm{V}: \mathrm{C} \rightarrow \mathrm{C}$ is l-Lipschitzian with constant $\mathrm{l} \in[0, \infty)$; 
- $\mathrm{G}: \mathrm{C} \rightarrow \mathrm{C}$ is a $\rho$-Lipschitzian and $\eta$-strongly monotone mapping with constants $\rho>0$ and $\eta>0$;

- constants $\mu, l, \tau$, and $\gamma$ satisfy $0<\mu<\frac{2 \eta}{\rho^{2}}$ and $0 \leqslant \gamma l<\tau$, where $\tau=1-\sqrt{1-\mu\left(2 \eta-\mu \rho^{2}\right)}$;

- $\mathrm{F}_{1}$ and $\mathrm{F}_{2}: \mathrm{C} \rightarrow \mathrm{H}$ are continuous monotone mappings;

- $\Omega$ is the solution set of GSVI (1.3) for $F_{1}$ and $F_{2}$;

- $\mathrm{F}_{1 \lambda}: \mathrm{H} \rightarrow \mathrm{C}$ is a mapping defined by

$$
\mathrm{F}_{1 \lambda} x=\left\{z \in \mathrm{C}:\left\langle y-z, \mathrm{~F}_{1} z\right\rangle+\frac{1}{\lambda}\langle y-z, z-x\rangle \geqslant 0, \quad \forall \mathrm{y} \in \mathrm{C}\right\}
$$

for $\lambda>0$;

- $\mathrm{F}_{2 v}: \mathrm{H} \rightarrow \mathrm{C}$ is a mapping defined by

$$
\mathrm{F}_{2 \gamma} x=\left\{z \in C:\left\langle y-z, F_{2} z\right\rangle+\frac{1}{v}\langle y-z, z-x\rangle \geqslant 0, \quad \forall y \in C\right\}
$$

for $v>0$;

- $\mathrm{R}: \mathrm{H} \rightarrow \mathrm{C}$ is a mapping defined by $\mathrm{Rx}=\mathrm{F}_{1 \lambda} \mathrm{F}_{2 \gamma} x$ for each $x \in \mathrm{H}$;

- $\mathrm{T}: \mathrm{C} \rightarrow \mathrm{C}$ is a continuous pseudocontractive mapping such that $\mathrm{Fix}(\mathrm{T}) \neq \emptyset$;

- $\mathrm{T}_{\mathrm{r}_{\mathrm{t}}}: \mathrm{H} \rightarrow \mathrm{C}$ is a mapping defined by

$$
\mathrm{T}_{\mathrm{r}_{\mathrm{t}}} x=\left\{z \in \mathrm{C}:\langle\mathrm{y}-z, \mathrm{~T} z\rangle-\frac{1}{\mathrm{r}_{\mathrm{t}}}\left\langle\mathrm{y}-z,\left(1+\mathrm{r}_{\mathrm{t}}\right) z-x\right\rangle \leqslant 0, \quad \forall \mathrm{y} \in \mathrm{C}\right\}
$$

for $r_{t} \in(0, \infty), t \in(0,1)$, and $\liminf _{t \rightarrow 0} r_{t}>0$;

- $\mathrm{T}_{\mathrm{r}_{\mathrm{n}}}: \mathrm{H} \rightarrow \mathrm{C}$ is a mapping defined by

$$
\mathrm{T}_{\mathrm{r}_{\mathrm{n}}} x=\left\{z \in \mathrm{C}:\langle\mathrm{y}-z, \mathrm{~T} z\rangle-\frac{1}{\mathrm{r}_{\mathrm{n}}}\left\langle\mathrm{y}-z,\left(1+\mathrm{r}_{\mathrm{n}}\right) z-x\right\rangle \leqslant 0, \quad \forall \mathrm{y} \in \mathrm{C}\right\}
$$

for $r_{n} \in(0, \infty)$ and $\liminf _{n \rightarrow \infty} r_{n}>0$;

- $\Omega \cap \operatorname{Fix}(T) \neq \emptyset$.

By Lemma 2.7 and Lemma 2.8, we note that $F_{1 \lambda}, F_{2 v}, T_{r_{t}}$, and $T_{r_{n}}$ are nonexpansive and

$$
\operatorname{Fix}\left(\mathrm{T}_{\mathrm{r}_{\mathfrak{n}}}\right)=\operatorname{Fix}(\mathrm{T})=\operatorname{Fix}\left(\mathrm{T}_{\mathrm{r}_{\mathrm{t}}}\right) .
$$

First, we prove that the problem (1.3) is equivalent to a fixed point problem of nonexpansive mapping.

Proposition 3.1. Let $\mathrm{C}$ be a closed convex subset of a real Hilbert space $\mathrm{H}$. For given $x^{*}, \mathrm{y}^{*} \in \mathrm{C},\left(x^{*}, \mathrm{y}^{*}\right)$ is a solution of GSVI (1.3) for continuous monotone mappings $F_{1}$ and $F_{2}$ if and only if $x^{*}$ is a fixed point of the mapping $\mathrm{R}: \mathrm{H} \rightarrow \mathrm{C}$ defined by

$$
\mathrm{R} x=\mathrm{F}_{1 \lambda} \mathrm{F}_{2 \gamma} x, \quad \forall x \in \mathrm{H},
$$

where $\mathrm{y}^{*}=\mathrm{F}_{2 \gamma} \mathrm{x}^{*}$.

Proof.

$$
\begin{cases}\left\langle\lambda F_{1} x^{*}+x^{*}-y^{*}, x-x^{*}\right\rangle \geqslant 0, & \forall x \in C \\ \left\langle v F_{2} y^{*}+y^{*}-x^{*}, x-y^{*}\right\rangle \geqslant 0, & \forall x \in C\end{cases}
$$

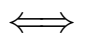

$$
\left\{\begin{aligned}
& \left\langle\lambda F_{1} x^{*}+x^{*}-y^{*}, x-x^{*}\right\rangle \geqslant 0, \quad \forall x \in C, \\
\Longleftrightarrow & \left\langle x-x^{*}, \lambda F_{1} x^{*}\right\rangle+\left\langle x-x^{*}, x^{*}-y^{*}\right\rangle \geqslant 0, \quad \forall x \in C, \\
\Longleftrightarrow & \left\langle x-x^{*}, F_{1} x^{*}\right\rangle+\frac{1}{\lambda}\left\langle x-x^{*}, x^{*}-y^{*}\right\rangle \geqslant 0, \quad x \in C, \\
\Longleftrightarrow & x^{*}=F_{1 \lambda} y^{*}
\end{aligned}\right.
$$


and

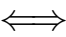

$$
\left\{\begin{aligned}
& \left\langle v F_{2} y^{*}+y^{*}-x^{*}, x-y^{*}\right\rangle \geqslant 0, \quad \forall x \in C, \\
\Longleftrightarrow & \left\langle x-y^{*}, v F_{2} y^{*}\right\rangle+\left\langle x-y^{*}, y^{*}-x^{*}\right\rangle \geqslant 0, \quad \forall x \in C, \\
\Longleftrightarrow & \left\langle x-y^{*}, F_{2} y^{*}\right\rangle+\frac{1}{v}\left\langle x-y^{*}, y^{*}-x^{*}\right\rangle \geqslant 0, \quad x \in C, \\
\Longleftrightarrow & y^{*}=F_{2 v} x^{*}
\end{aligned}\right.
$$

$$
x^{*}=F_{1 \lambda} y^{*}=F_{1 \lambda} F_{2 \gamma} x^{*}=R x^{*} .
$$

Remark 3.2. We note that since the mappings $F_{1 \lambda}$ and $F_{2 v}$ are firmly nonexpansive by Lemma 2.7, the mapping $\mathrm{R}: \mathrm{H} \rightarrow \mathrm{C}$ in Proposition 3.1 is nonexpansive.

Now, we introduce the following composite algorithm that generates a net $\left\{x_{t}\right\}$ in an implicit way:

$$
x_{t}=\left(I-\theta_{t} A\right) T_{r_{t}} R x_{t}+\theta_{t}\left[t \gamma V x_{t}+(I-t \mu G) T_{r_{t}} R x_{t}\right],
$$

where $t \in\left(0, \min \left\{1, \frac{2-\bar{\gamma}}{\tau-\gamma l}\right\}\right)$ and $\theta_{t} \in\left(0,\|A\|^{-1}\right]$.

For $t \in\left(0, \min \left\{1, \frac{2-\bar{\gamma}}{\tau-\gamma l}\right\}\right)$ and $\theta_{t} \in\left(0,\|A\|^{-1}\right]$, consider a mapping $Q_{t}: C \rightarrow C$ defined by

$$
\mathrm{Q}_{\mathrm{t}} x=\left(\mathrm{I}-\theta_{\mathrm{t}} A\right) \mathrm{T}_{\mathrm{r}_{\mathrm{t}}} \mathrm{Rx}+\theta_{\mathrm{t}}\left[\mathrm{t} \gamma \mathrm{V} x+(\mathrm{I}-\mathrm{t} \mu \mathrm{G}) \mathrm{T}_{\mathrm{r}_{\mathrm{t}}} \mathrm{Rx}\right], \quad \forall x \in \mathrm{C} .
$$

By the same argument as in [6] along with Lemma 2.5 and Lemma 2.6, it is easy to see that $Q_{t}$ is a contractive mapping with constant $1-\theta_{t}(\bar{\gamma}-1+t(\tau-\gamma l))$. By the Banach Contraction Principle, $Q_{t}$ has a unique fixed point, denoted $x_{t}$, which uniquely solves the fixed point equation (3.1).

We summarize the basic properties of $\left\{x_{t}\right\}$, which can be proved by the same method as in [6]. We include only the proof of (iv).

Proposition 3.3. Let $\left\{x_{\mathrm{t}}\right\}$ be defined via (3.1). Then

(i) $\left\{x_{\mathrm{t}}\right\}$ is bounded for $\mathrm{t} \in\left(0, \min \left\{1, \frac{2-\bar{\gamma}}{\tau-\gamma \mathrm{l}}\right\}\right)$;

(ii) $\lim _{\mathrm{t} \rightarrow 0}\left\|\mathrm{x}_{\mathrm{t}}-\mathrm{T}_{\mathrm{r}_{\mathrm{t}}} \mathrm{R} \mathrm{x}_{\mathrm{t}}\right\|=0$ provided $\lim _{\mathrm{t} \rightarrow 0} \theta_{\mathrm{t}}=0$;

(iii) $\lim _{t \rightarrow 0}\left\|x_{t}-y_{t}\right\|=0$, where $y_{t}=t \gamma V x_{t}+(I-t \mu G) T_{r_{t}} R x_{t}$;

(iv) $\lim _{\mathrm{t} \rightarrow 0}\left\|x_{\mathrm{t}}-\mathrm{R} \mathrm{x}_{\mathrm{t}}\right\|=0$;

(v) $x_{\mathrm{t}}:\left(0, \min \left\{1, \frac{2-\bar{\gamma}}{\tau-\gamma \mathrm{l}}\right\}\right) \rightarrow \mathrm{H}$ is locally Lipschitzian provided $\theta_{\mathrm{t}}:\left(0, \min \left\{1, \frac{2-\bar{\gamma}}{\tau-\gamma \mathrm{l}}\right\}\right) \rightarrow\left(0,\|\mathrm{~A}\|^{-1}\right]$ is locally Lipschitzian, and $r_{t}:\left(0, \min \left\{1, \frac{2-\bar{\gamma}}{\tau-\gamma l}\right\}\right) \rightarrow(0, \infty)$ is locally Lipschitzian;

(vi) $x_{t}$ defines a continuous path from $\left(0, \min \left\{1, \frac{2-\bar{\gamma}}{\tau-\gamma l}\right\}\right)$ into $\mathrm{H}$ provided $\theta_{\mathrm{t}}:\left(0, \min \left\{1, \frac{2-\bar{\gamma}}{\tau-\gamma \mathrm{l}}\right\}\right) \rightarrow\left(0,\|\mathrm{~A}\|^{-1}\right]$ is continuous, and $r_{\mathrm{t}}:\left(0, \min \left\{1, \frac{2-\bar{\gamma}}{\tau-\gamma l}\right\}\right) \rightarrow(0, \infty)$ is continuous.

Proof. (iv) Let $z_{t}=R x_{t}$, let $y_{t}=t \gamma V x_{t}+(I-t \mu G) T_{r_{t}} R x_{t}$ and let $p \in \Omega \cap$ Fix $(T)$. Since $z_{t}=R x_{t}, p=R p$ and $\mathrm{T}_{\mathrm{r}_{t}} \mathrm{p}=\mathrm{p}$, from Lemma 2.1 we have

$$
\begin{aligned}
\left\|y_{t}-p\right\|^{2} & =\left\|t\left(\gamma \vee x_{t}-\mu G p\right)+(I-t \mu G) T_{r_{t}} z_{t}-(I-t \mu G) p\right\|^{2} \\
& \leqslant\left(t\left\|\gamma \vee x_{t}-\mu G p\right\|+\left\|(I-t \mu G) T_{r_{t}} z_{t}-(I-t \mu G) T_{r_{t}} p\right\|\right)^{2} \\
& \leqslant t\left\|\gamma \vee x_{t}-\mu G p\right\|^{2}+(1-t \tau)\left\|z_{t}-p\right\|^{2}+2 t(1-t \tau)\left\|\gamma \vee x_{t}-\mu G p\right\|\left\|z_{t}-p\right\| .
\end{aligned}
$$

Moreover, from (2.2), we deduce

$$
\begin{aligned}
\left\|z_{t}-p\right\|^{2} & =\left\|R x_{t}-p\right\|^{2} \\
& \leqslant\left\|x_{t}-p\right\|^{2} \\
& =\left\langle x_{t}-p, x_{t}-p\right\rangle \\
& =\left\langle z_{t}-p, x_{t}-p\right\rangle+\left\langle x_{t}-z_{t}, x_{t}-p\right\rangle \\
& \leqslant \frac{1}{2}\left[\left\|x_{t}-p\right\|^{2}+\left\|z_{t}-p\right\|^{2}-\left\|x_{t}-z_{t}\right\|^{2}\right]+\left\|x_{t}-p\right\|\left\|x_{t}-z_{t}\right\|,
\end{aligned}
$$


and hence

$$
\left\|z_{t}-p\right\|^{2} \leqslant\left\|x_{t}-p\right\|^{2}-\left\|x_{t}-z_{t}\right\|^{2}+2\left\|x_{t}-p\right\|\left\|x_{t}-z_{t}\right\| .
$$

Thus, from (3.2) and (3.3), we derive

$$
\begin{aligned}
\left\|y_{t}-p\right\|^{2} \leqslant & t\left\|\gamma \vee x_{t}-\mu G p\right\|^{2}+(1-t \tau)\left\|z_{t}-p\right\|^{2}+2 t(1-t \tau)\left\|\gamma \vee x_{t}-\mu G p\right\|\left\|z_{t}-p\right\| \\
\leqslant & t\left\|\gamma \vee x_{t}-\mu G p\right\|^{2}+\left\|x_{t}-p\right\|^{2}-(1-t \tau)\left(\left\|x_{t}-z_{t}\right\|^{2}-2\left\|x_{t}-p\right\|\left\|x_{t}-z_{t}\right\|\right) \\
& +2 t(1-t \tau)\left\|\gamma V x_{t}-\mu G p\right\|\left\|z_{t}-p\right\| .
\end{aligned}
$$

This implies that

$$
\begin{aligned}
& (1-t \tau)\left\|x_{t}-z_{t}\right\|\left(\left\|x_{t}-z_{t}\right\|-2\left\|x_{t}-p\right\|\right) \\
& \quad \leqslant t\left\|\gamma \vee x_{t}-\mu G p\right\|^{2}+\left(\left\|x_{t}-p\right\|+\left\|y_{t}-p\right\|\right)\left(\left\|x_{t}-p\right\|-\left\|y_{t}-p\right\|\right)+2 t\left\|\gamma \vee x_{t}-\mu G p\right\|\left\|z_{t}-p\right\| \\
& \quad \leqslant t\left\|\gamma \vee x_{t}-\mu G p\right\|^{2}+\left(\left\|x_{t}-p\right\|+\left\|y_{t}-p\right\|\right)\left\|x_{t}-y_{t}\right\|+2 t\left\|\gamma \vee x_{t}-\mu G p\right\|\left\|z_{t}-p\right\| .
\end{aligned}
$$

Since $t \rightarrow 0$ and $\left\|x_{t}-y_{t}\right\| \rightarrow 0$ by (iii), we get

$$
\lim _{t \rightarrow 0}\left\|x_{t}-z_{t}\right\|\left(\left\|x_{t}-z_{t}\right\|-2\left\|x_{t}-p\right\|\right)=0 .
$$

In general, $\lim _{t \rightarrow 0}\left(\left\|x_{t}-z_{t}\right\|-2\left\|x_{t}-p\right\|\right) \neq 0$. So, we conclude

$$
\lim _{t \rightarrow 0}\left\|x_{t}-R x_{t}\right\|=\lim _{t \rightarrow 0}\left\|x_{t}-z_{t}\right\|=0 .
$$

We prove the following theorem for strong convergence of the net $\left\{x_{t}\right\}$ as $t \rightarrow 0$, which guarantees the existence of solutions of the variational inequality (3.4) below.

Theorem 3.4. Let the net $\left\{x_{\mathrm{t}}\right\}$ be defined via (3.1). If $\lim _{\mathrm{t} \rightarrow 0} \theta_{\mathrm{t}}=0$, then $\mathrm{x}_{\mathrm{t}}$ converges strongly to $\widetilde{x}$ in $\Omega \cap \mathrm{Fix}(\mathrm{T})$ as $\mathrm{t} \rightarrow 0$, which solves the variational inequality

$$
\langle(A-I) \widetilde{x}, \widetilde{x}-p\rangle \leqslant 0, \quad \forall p \in \Omega \cap \operatorname{Fix}(T) .
$$

Equivalently, we have

$$
\mathrm{P}_{\Omega \cap \mathrm{Fix}(\mathrm{T})}(2 \mathrm{I}-\mathrm{A}) \widetilde{\mathrm{x}}=\widetilde{\mathrm{x}} .
$$

Proof. We first note that the uniqueness of a solution of the variational inequality (3.4) is a consequence of the strong monotonicity of $A-I$ (by Lemma 2.4). See $[1,6]$ for this fact.

Next, we prove that $x_{t} \rightarrow \widetilde{x}$ as $t \rightarrow 0$. Let $z_{t}=R x_{t}$. Observing Fix $(T)=\operatorname{Fix}\left(T_{r_{t}}\right)$ (by Lemma 2.8 (iii)) and $\operatorname{Fix}(R)=\Omega$ (by Proposition 3.1), from (3.1), we write for given $p \in \Omega \cap \operatorname{Fix}(T)$,

$$
\begin{aligned}
x_{t}-p & =\left(I-\theta_{t} A\right) T_{r_{t}} z_{t}-\left(I-\theta_{t} A\right) T_{r_{t}} p+\theta_{t}\left[t \gamma V x_{t}+(I-t \mu G) T_{r_{t}} z_{t}-p\right]+\theta_{t}(I-A) p \\
& =\left(I-\theta_{t} A\right)\left(T_{r_{t}} z_{t}-T_{r_{t}} p\right)+\theta_{t}\left[t\left(\gamma V x_{t}-\mu G p\right)+(I-t \mu G) T_{r_{t}} z_{t}-(I-t \mu G) p\right]+\theta_{t}(I-A) p,
\end{aligned}
$$

to derive that

$$
\begin{aligned}
\left\|x_{t}-p\right\|^{2}= & \left\langle\left(I-\theta_{t} A\right)\left(T_{r_{t}} z_{t}-T_{r_{t}} p\right), x_{t}-p\right\rangle+\theta_{t}\left[t\left\langle\gamma V x_{t}-\mu G p, x_{t}-p\right\rangle\right. \\
& \left.+\left\langle(I-t \mu G) T_{r_{t}} z_{t}-(I-t \mu G) p, x_{t}-p\right\rangle\right]+\theta_{t}\left\langle(I-A) p, x_{t}-p\right\rangle \\
\leqslant & \left(1-\theta_{t} \bar{\gamma}\right)\left\|z_{t}-p\right\|\left\|x_{t}-p\right\| \\
& +\theta_{t}\left[(1-t \tau)\left\|z_{t}-p\right\|\left\|x_{t}-p\right\|+t \gamma l\left\|x_{t}-p\right\|^{2}+t\left\langle\gamma V p-\mu G p, x_{t}-p\right\rangle\right] \\
& +\theta_{t}\left\langle(I-A) p, x_{t}-p\right\rangle \\
\leqslant & \left(1-\theta_{t} \bar{\gamma}\right)\left\|x_{t}-p\right\|^{2}+\theta_{t}\left[(1-t \tau)\left\|x_{t}-p\right\|^{2}+t \gamma l\left\|x_{t}-p\right\|^{2}+t\left\langle\gamma V p-\mu G p, x_{t}-p\right\rangle\right] \\
& +\theta_{t}\left\langle(I-A) p, x_{t}-p\right\rangle \\
= & {\left[1-\theta_{t}(\bar{\gamma}-1+t(\tau-\gamma l))\right]\left\|x_{t}-p\right\|^{2}+\theta_{t}\left(t\left\langle\gamma V p-\mu G p, x_{t}-p\right\rangle+\left\langle(I-A) p, x_{t}-p\right\rangle\right) . }
\end{aligned}
$$


Therefore,

$$
\left\|x_{t}-p\right\|^{2} \leqslant \frac{1}{\bar{\gamma}-1+t(\tau-\gamma l)}\left(t\left\langle\gamma V p-\mu G p, x_{t}-p\right\rangle+\left\langle(I-A) p, x_{t}-p\right\rangle\right) .
$$

Since $\left\{x_{t}\right\}$ is bounded as $t \rightarrow 0$ (by Proposition 3.3 (i)), there exists a subsequence $\left\{t_{n}\right\}$ in $\left(0, \min \left\{1, \frac{2-\bar{\gamma}}{\tau-\gamma l}\right\}\right)$ such that $t_{n} \rightarrow 0$ and $x_{t_{n}} \rightarrow x^{*}$. First of all, we prove that $x^{*} \in \Omega \cap \operatorname{Fix}(T)$. To this end, we divide its proof into four steps.

Step 1. From Proposition 3.3 (iv), we know that $\lim _{n \rightarrow \infty}\left\|x_{t_{n}}-R x_{t_{n}}\right\|=\lim _{n \rightarrow \infty}\left\|x_{t_{n}}-z_{t_{n}}\right\|=0$.

Step 2. We show that $\lim _{n \rightarrow \infty}\left\|u_{t_{n}}-z_{t_{n}}\right\|=0$, where $u_{t_{n}}=T_{r_{t_{n}}} z_{t_{n}}$. Indeed, from Proposition 3.3 (ii) and Step 1, it follows that

$$
\left\|u_{t_{n}}-z_{t_{n}}\right\| \leqslant\left\|u_{t_{n}}-x_{t_{n}}\right\|+\left\|x_{t_{n}}-z_{t_{n}}\right\| \rightarrow 0 \quad(\text { as } n \rightarrow \infty) .
$$

Step 3. We show that $x^{*} \in \Omega$. In fact, since $x_{n} \rightarrow x^{*}$ and $x_{n}-R x_{n} \rightarrow 0$ by Step 1 , from Lemma 2.3 (Demiclosedness principle), we get $x^{*}=R x^{*}$, that is, $x^{*} \in \operatorname{Fix}(\mathrm{R})$. Thus, by Proposition 3.1, we have $x^{*} \in \Omega$.

Step 4. We have $x^{*} \in \operatorname{Fix}(T)$ by the same argument as in the proof of [18, Theorem 3.1]. We include its proof for the sake of completeness. In fact, from the definition of $u_{t_{n}}=T_{r_{t_{n}}} z_{t_{n}}$, we have

$$
\left\langle y-u_{t_{n}}, T u_{t_{n}}\right\rangle-\frac{1}{r_{t_{n}}}\left\langle y-u_{t_{n}},\left(1+r_{t_{n}}\right) u_{t_{n}}-z_{t_{n}}\right\rangle \leqslant 0, \quad \forall y \in C .
$$

Put $w_{\mathrm{t}}=\mathrm{t} v+(1-\mathrm{t}) x^{*}$ for all $\mathrm{t} \in(0,1]$ and $v \in \mathrm{C}$. Then, $w_{\mathrm{t}} \in \mathrm{C}$ and from (3.6) and pseudocontractivity of $T$, it follows that

$$
\begin{aligned}
\left\langle u_{t_{n}}-w_{t}, T w_{t}\right\rangle & \geqslant\left\langle u_{t_{n}}-w_{t}, T w_{t}\right\rangle+\left\langle w_{t}-u_{t_{n}}, T u_{t_{n}}\right\rangle-\frac{1}{r_{t_{n}}}\left\langle w_{t}-u_{t_{n}},\left(1+r_{t_{n}}\right) u_{t_{n}}-z_{t_{n}}\right\rangle \\
& =-\left\langle w_{t}-u_{t_{n}}, T w_{t}-T u_{t_{n}}\right\rangle-\frac{1}{r_{t_{n}}}\left\langle w_{t}-u_{t_{n}}, u_{t_{n}}-z_{t_{n}}\right\rangle-\left\langle w_{t}-u_{t_{n}}, u_{t_{n}}\right\rangle \\
& \geqslant-\left\|w_{t}-u_{t_{n}}\right\|^{2}-\frac{1}{r_{t_{n}}}\left\langle w_{t}-u_{t_{n}}, u_{t_{n}}-z_{t_{n}}\right\rangle-\left\langle w_{t}-u_{t_{n}}, u_{t_{n}}\right\rangle \\
& =-\left\langle w_{t}-u_{t_{n}}, w_{t}\right\rangle-\left\langle w_{t}-u_{t_{n}}, \frac{u_{t_{n}}-z_{t_{n}}}{r_{t_{n}}}\right\rangle
\end{aligned}
$$

By Step 2, we get $\frac{u_{t_{n}}-z_{t_{n}}}{r_{t_{n}}} \rightarrow 0$ as $n \rightarrow \infty$. Moreover, since $x_{t_{n}} \rightarrow x^{*}$, by Step 1 and Step 2, we have $u_{t_{n}} \rightarrow x^{*}$ as $n \rightarrow \infty$. Therefore, from (3.7), as $n \rightarrow \infty$, it follows that

$$
\left\langle x^{*}-w_{\mathrm{t}}, T w_{\mathrm{t}}\right\rangle \geqslant\left\langle x^{*}-w_{\mathrm{t}}, w_{\mathrm{t}}\right\rangle,
$$

and hence

$$
-\left\langle v-x^{*}, T w_{t}\right\rangle \geqslant-\left\langle v-x^{*}, w_{t}\right\rangle, \quad \forall v \in \mathrm{C} .
$$

Letting $t \rightarrow 0$ and using the fact that $T$ is continuous, we get

$$
-\left\langle v-x^{*}, T x^{*}\right\rangle \geqslant-\left\langle v-x^{*}, x^{*}\right\rangle, \quad \forall v \in \mathrm{C} .
$$

Now, let $v=T x^{*}$. Then we obtain $x^{*}=T x^{*}$ and hence $x^{*} \in \operatorname{Fix}(T)$. Therefore, $x^{*} \in \Omega \cap \operatorname{Fix}(T)$.

Now, we substitute $x^{*}$ for $p$ in (3.5) to obtain

$$
\left\|x_{t_{n}}-x^{*}\right\|^{2} \leqslant \frac{1}{\bar{\gamma}-1+t_{n}(\tau-\gamma l)}\left(t_{n}\left\langle\gamma V x^{*}-\mu G x^{*}, x_{t_{n}}-x^{*}\right\rangle+\left\langle(I-A) x^{*}, x_{t_{n}}-x^{*}\right\rangle\right) .
$$

Note that $x_{t_{n}} \rightarrow x^{*}$ and $\lim _{n \rightarrow \infty} t_{n}=0$. This fact and the inequality (3.8) imply that $x_{t_{n}} \rightarrow x^{*}$ strongly. 
Finally, we prove that $x^{*}$ is a solution of the variational inequality (3.4). In fact, putting $x_{t_{n}}$ in place of $x_{t}$ in (3.5) and taking the limit as $t_{n} \rightarrow 0$, we obtain

$$
\left\|x^{*}-p\right\|^{2} \leqslant \frac{1}{\bar{\gamma}-1}\left\langle(I-A) p, x^{*}-p\right\rangle, \quad \forall p \in \Omega \cap \operatorname{Fix}(T) .
$$

In particular, $x^{*}$ solves the following variational inequality

$$
x^{*} \in \Omega \cap \operatorname{Fix}(T), \quad\left\langle(A-I) p, x^{*}-p\right\rangle \leqslant 0, \quad \forall p \in \Omega \cap \operatorname{Fix}(T),
$$

or the equivalent dual variational inequality (see [12])

$$
x^{*} \in \Omega \cap \operatorname{Fix}(T), \quad\left\langle(A-I) x^{*}, x^{*}-p\right\rangle \leqslant 0, \quad \forall p \in \Omega \cap \operatorname{Fix}(T) .
$$

That is, $x^{*} \in \Omega \cap \operatorname{Fix}(T)$ is a solution of the variational inequality (3.4). Hence $x^{*}=\widetilde{x}$ by uniqueness. In a summary, we have shown that each cluster point of $\left\{x_{t}\right\}$ (at $t \rightarrow 0$ ) equals $\widetilde{x}$. Therefore $x_{t} \rightarrow \widetilde{x}$ as $t \rightarrow 0$. The variational inequality (3.4) can be written as

$$
\langle(2 I-A) \widetilde{x}-\tilde{x}, \widetilde{x}-p\rangle \geqslant 0, \quad \forall p \in \Omega \cap \operatorname{Fix}(T) .
$$

So, by (2.1), this is equivalent to the fixed point equation

$$
P_{\Omega \cap F i x(T)}(2 I-A) \widetilde{x}=\tilde{x} .
$$

This completes the proof.

Taking $\mathrm{G} \equiv \mathrm{I}$, the identity mapping, $\mu=1$ and $\gamma=1$ in Theorem 3.4, we have the following corollary.

Corollary 3.5. Let $\left\{x_{\mathrm{t}}\right\}$ be defined by

$$
x_{t}=\left(I-\theta_{t} A\right) T_{r_{t}} R x_{t}+\theta_{t}\left[t V x_{t}+(1-t) T_{r_{t}} R x_{t}\right]
$$

If $\lim _{\mathrm{t} \rightarrow 0} \theta_{\mathrm{t}}=0$, then $\left\{x_{\mathrm{t}}\right\}$ converges strongly as $\mathrm{t} \rightarrow 0$ to $\widetilde{\mathrm{x}}$ in $\Omega \cap \operatorname{Fix}(\mathrm{T})$, which is the unique solution of the variational inequality (3.4).

Taking $\mathrm{T} \equiv \mathrm{I}, \mathrm{G} \equiv \mathrm{I}, \mu=1$ and $\gamma=1$ in Theorem 3.4, we have the following corollary.

Corollary 3.6. Let $\left\{x_{\mathrm{t}}\right\}$ be defined by

$$
x_{t}=\left(I-\theta_{t} A\right) R x_{t}+\theta_{t}\left[t V x_{t}+(1-t) R x_{t}\right] .
$$

If $\lim _{\mathrm{t} \rightarrow 0} \theta_{\mathrm{t}}=0$, then $\left\{x_{\mathrm{t}}\right\}$ converges strongly as $\mathrm{t} \rightarrow 0$ to $\tilde{\mathrm{x}} \in \Omega$, which is the unique solution of the variational inequality

$$
\langle(A-I) \widetilde{x}, \widetilde{x}-p\rangle \leqslant 0, \quad \forall p \in \Omega .
$$

Proof. If $\mathrm{T} \equiv \mathrm{I}$, then $\mathrm{T}_{\mathrm{r}}$ in Lemma 2.8 is the identity mapping. Thus the result follows from Theorem 3.4.

Now, we propose the following composite algorithm which generates a sequence in an explicit way:

$$
\left\{\begin{array}{l}
y_{n}=\alpha_{n} \gamma V x_{n}+\left(I-\alpha_{n} \mu G\right) T_{r_{n}} R x_{n}, \\
x_{n+1}=\left(I-\beta_{n} A\right) T_{r_{n}} R x_{n}+\beta_{n} y_{n}, \quad \forall n \geqslant 0,
\end{array}\right.
$$

where $\left\{\alpha_{n}\right\} \in[0,1] ;\left\{\beta_{n}\right\} \subset(0,1] ;\left\{r_{n}\right\} \subset(0, \infty) ;$ and $x_{0} \in C$ is an arbitrary initial guess, and establish strong convergence of this sequence to $\widetilde{x} \in \Omega \cap \operatorname{Fix}(T)$, which is the unique solution of the variational inequality (3.4). 
Theorem 3.7. Let $\left\{x_{n}\right\}$ be the sequence generated by the explicit algorithm (3.10). Let $\left\{\alpha_{n}\right\},\left\{\beta_{n}\right\}$, and $\left\{r_{n}\right\}$ satisfy the following conditions:

(C1) $\left\{\alpha_{n}\right\} \subset[0,1]$ and $\left\{\beta_{n}\right\} \subset(0,1], \alpha_{n} \rightarrow 0$ and $\beta_{n} \rightarrow 0$ as $n \rightarrow \infty$;

(C2) $\sum_{n=0}^{\infty} \beta_{n}=\infty$;

(C3) $\sum_{n=0}^{\infty}\left|\alpha_{n+1}-\alpha_{n}\right|<\infty$, and $\left|\beta_{n+1}-\beta_{n}\right| \leqslant o\left(\beta_{n+1}\right)+\sigma_{n}, \quad \sum_{n=0}^{\infty} \sigma_{n}<\infty$ (the perturbed control condition);

(C4) $\left\{r_{n}\right\} \subset(0, \infty), \liminf _{n \rightarrow \infty} r_{n}>0$, and $\sum_{n=0}^{\infty}\left|r_{n+1}-r_{n}\right|<\infty$.

Then $\left\{x_{n}\right\}$ converges strongly to $\widetilde{x} \in \Omega \cap F i x(T)$, which is the unique solution of the variational inequality (3.4).

Proof. First, note that from the condition (C1), without loss of generality, we assume that $\alpha_{n} \tau<1, \beta_{n} \bar{\gamma}<1$ and $\frac{2 \beta_{n}(\bar{\gamma}-1)}{1-\beta_{n}}<1$ for all $n \geqslant 0$. Let $\tilde{x} \in \Omega \cap \operatorname{Fix}(T)$ be the unique solution of the variational inequality (3.4). (The existence of $\widetilde{x}$ follows from Theorem 3.4).

From now, we put $z_{n}=R x_{n}$ and $y_{n}=\alpha_{n} \gamma V x_{n}+\left(I-\alpha_{n} \mu G\right) T_{r_{n}} R x_{n}=\alpha_{n} \gamma V x_{n}+\left(I-\alpha_{n} \mu G\right) T_{n} z_{n}$. Let $p \in \Omega \cap \operatorname{Fix}(T)$. Then $p=\mathrm{T}_{\mathrm{r}_{n}} \mathrm{p}$ by Lemma 2.8 (iii) and $p=R p$ by Proposition 3.1. Moreover, from nonexpansivity of $F$, it follows that

$$
\left\|z_{n}-p\right\|=\left\|R x_{n}-R p\right\| \leqslant\left\|x_{n}-p\right\| .
$$

We divide the proof into several steps as follows.

Step 1. We show that $\left\{x_{n}\right\}$ is bounded. First of all, by (3.10), we deduce

$$
\begin{aligned}
\left\|y_{n}-p\right\| & =\left\|\alpha_{n} \gamma V x_{n}+\left(I-\alpha_{n} \mu G\right) T_{r_{n}} z_{n}-p\right\| \\
& =\left\|\alpha_{n}\left(\gamma \vee x_{n}-\mu G p\right)+\left(I-\alpha_{n} \mu G\right) T_{r_{n}} z_{n}-\left(I-\alpha_{n} \mu G\right) T_{r_{n}} p\right\| \\
& \leqslant\left(1-\alpha_{n}(\tau-\gamma l)\right)\left\|z_{n}-p\right\|+\alpha_{n}\|\gamma V p-\mu G p\| \\
& \leqslant\left(1-\alpha_{n}(\tau-\gamma l)\right)\left\|x_{n}-p\right\|+\alpha_{n}\|\gamma V p-\mu G p\| .
\end{aligned}
$$

So, we have

$$
\begin{aligned}
\left\|x_{n+1}-p\right\| & =\left\|\left(I-\beta_{n} A\right) T_{r_{n}} z_{n}+\beta_{n} y_{n}-p\right\| \\
& =\left\|\left(I-\beta_{n} A\right) T_{r_{n}} z_{n}-\left(I-\beta_{n} A\right) T_{r_{n}} p+\beta_{n}\left(y_{n}-p\right)+\beta_{n}(I-A) p\right\| \\
& \leqslant\left\|\left(I-\beta_{n} A\right) T_{r_{n}} z_{n}-\left(I-\beta_{n} A\right) T_{r_{n}} p\right\|+\beta_{n}\left\|y_{n}-p\right\|+\beta_{n}\|I-A\|\|p\| \\
& \leqslant\left(1-\beta_{n} \bar{\gamma}\right)\left\|z_{n}-p\right\|+\beta_{n}\left[\left(1-\alpha_{n}(\tau-\gamma l)\left\|z_{n}-p\right\|+\alpha_{n}\|\gamma V p-\mu G p\|\right]+\beta_{n}\|I-A\|\|p\|\right. \\
& \leqslant\left(1-\beta_{n} \bar{\gamma}\right)\left\|x_{n}-p\right\|+\beta_{n}\left[\left(1-\alpha_{n}(\tau-\gamma l)\right)\left\|x_{n}-p\right\|+\alpha_{n}\|\gamma V p-\mu G p\|\right]+\beta_{n}\|I-A\|\|p\| \\
& \leqslant\left(1-\beta_{n}(\bar{\gamma}-1)\right)\left\|x_{n}-p\right\|+\beta_{n}(\|\gamma V p-\mu G p\|+\|I-A\|\|p\|) \\
& =\left(1-\beta_{n}(\bar{\gamma}-1)\right)\left\|x_{n}-p\right\|+\beta_{n}(\bar{\gamma}-1) \frac{\|\gamma V p-\mu G p\|+\|I-A\|\|p\|}{\gamma-1} \\
& \leqslant \max \left\{\left\|x_{n}-p\right\|, \frac{\|\gamma V p-\mu G p\|+\|I-A\|\|p\|}{\bar{\gamma}-1}\right\} .
\end{aligned}
$$

By induction, we derive

$$
\left\|x_{n}-p\right\| \leqslant \max \left\{\left\|x_{0}-p\right\|, \frac{\|\gamma V p-\mu G p\|+\|I-A\|\|p\|}{\bar{\gamma}-1}\right\}, \quad \forall n \geqslant 0 .
$$

This implies that $\left\{x_{n}\right\}$ is bounded and so are $\left\{G x_{n}\right\},\left\{z_{n}\right\},\left\{T_{r_{n}} z_{n}\right\},\left\{\mathrm{GT}_{r_{n}} z_{n}\right\},\left\{V x_{n}\right\},\left\{A T_{r_{n}} z_{n}\right\}$ and $\left\{y_{n}\right\}$. As 
a consequence with the control condition (C1), we get

$$
\left\|x_{n+1}-T_{r_{n}} z_{n}\right\|=\beta_{n}\left\|y_{n}-A T_{r_{n}} z_{n}\right\| \rightarrow 0 \quad(n \rightarrow \infty) .
$$

Step 2. We show that $\lim _{n \rightarrow \infty}\left\|x_{n+1}-x_{n}\right\|=0$. To this end, let $z_{n}=R x_{n}, z_{n-1}=R x_{n-1}, u_{n}=T_{r_{n}} z_{n}$ and $u_{n-1}=T_{r_{n-1}} z_{n-1}$. Then we derive

$$
\left\langle y-u_{n-1}, T u_{n-1}\right\rangle-\frac{1}{r_{n-1}}\left\langle y-u_{n-1},\left(1+r_{n-1}\right) u_{n-1}-z_{n-1}\right\rangle \leqslant 0, \quad \forall y \in C,
$$

and

$$
\left\langle y-u_{n}, T u_{n}\right\rangle-\frac{1}{r_{n}}\left\langle y-u_{n},\left(1+r_{n}\right) u_{n}-z_{n}\right\rangle \leqslant 0, \quad \forall y \in C .
$$

Putting $y=u_{n}$ in (3.12) and $y=u_{n-1}$ in (3.13), we obtain

$$
\left\langle u_{n}-u_{n-1}, T u_{n-1}\right\rangle-\frac{1}{r_{n-1}}\left\langle u_{n}-u_{n-1},\left(1+r_{n-1}\right) u_{n-1}-z_{n-1}\right\rangle \leqslant 0,
$$

and

$$
\left\langle u_{n-1}-u_{n}, T u_{n}\right\rangle-\frac{1}{r_{n}}\left\langle u_{n-1}-u_{n},\left(1+r_{n}\right) u_{n}-z_{n}\right\rangle \leqslant 0 .
$$

Adding up (3.14) and (3.15), we have

$$
\left\langle u_{n}-u_{n-1}, T u_{n-1}-T u_{n}\right\rangle-\left\langle u_{n}-u_{n-1}, \frac{\left(1+r_{n-1}\right) u_{n-1}-z_{n-1}}{r_{n-1}}-\frac{\left(1+r_{n}\right) u_{n}-z_{n}}{r_{n}}\right\rangle \leqslant 0,
$$

which implies that

$$
\left\langle u_{n}-u_{n-1},\left(u_{n}-T u_{n}\right)-\left(u_{n-1}-T u_{n-1}\right)\right\rangle-\left\langle u_{n}-u_{n-1}, \frac{u_{n-1}-z_{n-1}}{r_{n-1}}-\frac{u_{n}-z_{n}}{r_{n}}\right\rangle \leqslant 0 .
$$

Now, using the fact that $T$ is pseudocontractive, we get

$$
\left\langle u_{n}-u_{n-1}, \frac{u_{n-1}-z_{n-1}}{r_{n-1}}-\frac{u_{n}-z_{n}}{r_{n}}\right\rangle \geqslant 0,
$$

and hence

$$
\left\langle u_{n}-u_{n-1}, u_{n-1}-u_{n}+u_{n}-z_{n-1}-\frac{r_{n-1}}{r_{n}}\left(u_{n}-z_{n}\right)\right\rangle \geqslant 0 .
$$

Without loss of generality, let us assume that there exists a real number $r_{n}>b>0$, for all $n \geqslant 0$. Then, by (3.16), we have

$$
\begin{aligned}
\left\|u_{n}-u_{n-1}\right\|^{2} & \leqslant\left\langle u_{n}-u_{n-1}, z_{n}-z_{n-1}+\left(1-\frac{r_{n-1}}{r_{n}}\right)\left(u_{n}-z_{n}\right)\right\rangle \\
& \leqslant\left\|u_{n}-u_{n-1}\right\|\left\{\left\|z_{n}-z_{n-1}\right\|+\frac{1}{r_{n}}\left|r_{n}-r_{n-1}\right|\left\|u_{n}-z_{n}\right\|\right\},
\end{aligned}
$$

and hence

$$
\left\|\mathrm{T}_{r_{n}} z_{n}-\mathrm{T}_{r_{n-1}} z_{n-1}\right\| \leqslant\left\|x_{n}-x_{n-1}\right\|+\frac{1}{b}\left|r_{n}-r_{n-1}\right| M_{1},
$$

where $M_{1}=\sup \left\{\left\|u_{n}-z_{n}\right\|: n \geqslant 0\right\}$.

Now, simple calculations yield that

$$
\begin{aligned}
y_{n}-y_{n-1}= & \alpha_{n} \gamma V x_{n}+\left(I-\alpha_{n} \mu G\right) T_{r_{n}} z_{n}-\alpha_{n-1} \gamma V x_{n-1}-\left(I-\alpha_{n-1} \mu G\right) T_{r_{n-1}} z_{n-1} \\
= & \left(\alpha_{n}-\alpha_{n-1}\right)\left(\gamma V x_{n-1}-\mu G T_{r_{n-1}} z_{n-1}\right)+\alpha_{n} \gamma\left(V x_{n}-V x_{n-1}\right) \\
& +\left(I-\alpha_{n} \mu G\right) T_{r_{n}} z_{n}-\left(I-\alpha_{n} \mu G\right) T_{r_{n-1}} z_{n-1} .
\end{aligned}
$$


By (3.17) and Lemma 2.6, we obtain

$$
\begin{aligned}
\left\|y_{n}-y_{n-1}\right\| \leqslant & \left|\alpha_{n}-\alpha_{n-1}\right|\left(\gamma\left\|V x_{n-1}\right\|+\mu\left\|G_{r_{n-1}} z_{n-1}\right\|\right) \\
& +\alpha_{n} \gamma l\left\|x_{n}-x_{n-1}\right\|+\left(1-\tau \alpha_{n}\right)\left\|T_{r_{n}} z_{n}-\mathrm{T}_{r_{n-1}} z_{n-1}\right\| \\
\leqslant & \left|\alpha_{n}-\alpha_{n-1}\right|\left(\gamma\left\|V x_{n-1}\right\|+\mu\left\|G T_{r_{n-1}} z_{n-1}\right\|\right) \\
& +\alpha_{n} \gamma l\left\|x_{n}-x_{n-1}\right\|+\left(1-\tau \alpha_{n}\right)\left\|x_{n}-x_{n-1}\right\|+\frac{1}{b}\left|r_{n}-r_{n-1}\right| M_{1} \\
= & \left|\alpha_{n}-\alpha_{n-1}\right|\left(\gamma\left\|V x_{n-1}\right\|+\mu\left\|G T_{n-1} z_{n-1}\right\|\right) \\
& +\left(1-\alpha_{n}(\tau-\gamma l)\left\|x_{n}-x_{n-1}\right\|+\frac{1}{b}\left|r_{n}-r_{n-1}\right|\left(M_{1}+M_{2}\right)\right. \\
\leqslant & \left\|x_{n}-x_{n-1}\right\|+\left|\alpha_{n}-\alpha_{n-1}\right| M_{2}+\frac{1}{b}\left|r_{n}-r_{n-1}\right| M_{1},
\end{aligned}
$$

where $M_{2}=\sup \left\{\gamma\left\|V x_{n}\right\|+\mu\left\|G_{r_{n}} z_{n}\right\|: n \geqslant 0\right\}$. By (3.18) and Lemma 2.5, we derive

$$
\begin{aligned}
\left\|x_{n+1}-x_{n}\right\|= & \left\|\left(I-\beta_{n} A\right) T_{r_{n}} z_{n}+\beta_{n} y_{n}-\left(I-\beta_{n-1} A\right) T_{r_{n-1}} z_{n-1}-\beta_{n-1} y_{n-1}\right\| \\
\leqslant & \left\|\left(I-\beta_{n} A\right)\left(T_{r_{n}} z_{n}-T_{r_{n-1}} z_{n-1}\right)\right\| \\
& +\left|\beta_{n}-\beta_{n-1}\right|\|A\|||\left|T_{r_{n-1}} z_{n-1}\right|+\beta_{n}\left\|y_{n}-y_{n-1}|+| \beta_{n}-\beta_{n-1}|| y_{n-1}\right\| \\
\leqslant & \left(1-\beta_{n} \bar{\gamma}\right) \| T_{r_{n}} z_{n}-T_{r_{n-1}} z_{n-1} \mid \\
& +\beta_{n}\left(\| x_{n}-x_{n-1}||+\alpha_{n}-\alpha_{n-1}\left|M_{2}+\frac{1}{b}\right| r_{n}-r_{n-1} \mid M_{1}\right)+\left|\beta_{n}-\beta_{n-1}\right| M_{3} \\
\leqslant & \left(1-\beta_{n} \bar{\gamma}\right)\left(\| x_{n}-x_{n-1}||+\frac{1}{b}\left|r_{n}-r_{n-1}\right| M_{1}\right) \\
& +\beta_{n}\left(\| x_{n}-x_{n-1}||+\left|\alpha_{n}-\alpha_{n-1}\right| M_{2}+\frac{1}{b}\left|r_{n}-r_{n-1}\right| M_{1}\right)+\left|\beta_{n}-\beta_{n-1}\right| M_{3} \\
\leqslant & \left(1-\beta_{n}(\bar{\gamma}-1)\right)\left\|x_{n}-x_{n-1}\right\|+\left|\beta_{n}-\beta_{n-1}\right| M_{3} \\
& +\left|\alpha_{n}-\alpha_{n-1}\right| M_{3}+\frac{2}{b}\left|r_{n}-r_{n-1}\right| M_{1} \\
\leqslant & \left(1-\beta_{n}(\bar{\gamma}-1)\right)\left\|x_{n}-x_{n-1}\right\|+\left(o\left(\beta_{n}\right)+\sigma_{n-1}\right) M_{3} \\
& +\left|\alpha_{n}-\alpha_{n-1}\right| M_{2}+\frac{2}{b}\left|r_{n}-r_{n-1}\right| M_{1},
\end{aligned}
$$

where $M_{3}=\sup \left\{\|A\|\left\|T_{r_{n}} z_{n}\right\|+\left\|y_{n}\right\|: n \geqslant 0\right\}$. By taking $s_{n+1}=\left\|x_{n+1}-x_{n}\right\|, \omega_{n}=\beta_{n}(\bar{\gamma}-1), \omega_{n} \delta_{n}=$ $M_{4} \mathrm{o}\left(\beta_{n}\right)$ and $r_{n}=\left(\sigma_{n-1} M_{3}+\left|\alpha_{n}-\alpha_{n-1}\right| M_{2}+\frac{2}{b}\left|r_{n}-r_{n-1}\right| M_{1}\right)$, from (3.19) we deduce

$$
s_{n+1} \leqslant\left(1-\omega_{n}\right) s_{n}+\omega_{n} \delta_{n}+r_{n} .
$$

Hence, by the conditions (C2), (C3), (C4), and Lemma 2.2, we obtain

$$
\lim _{n \rightarrow \infty}\left\|x_{n+1}-x_{n}\right\|=0
$$

Step 3. We show that $\lim _{n \rightarrow \infty}\left\|x_{n+1}-y_{n}\right\|=0$. Indeed, from (3.11) and condition (C1), we derive

$$
\begin{aligned}
\left\|x_{n+1}-y_{n}\right\| & \leqslant\left\|x_{n+1}-T_{r_{n}} z_{n}\right\|+\left\|T_{r_{n}} z_{n}-y_{n}\right\| \\
& =\beta_{n}\left\|y_{n}-A T_{r_{n}} z_{n}\right\|+\alpha_{n}\left\|\gamma V x_{n}-\mu G T_{r_{n}} z_{n}\right\| \rightarrow 0 \quad(\text { as } n \rightarrow \infty) .
\end{aligned}
$$

Step 4. We show that $\lim _{n \rightarrow \infty}\left\|x_{n}-y_{n}\right\|=0$. In fact, by Step 2 and Step 3, we get

$$
\left\|x_{n}-y_{n}\right\| \leqslant\left\|x_{n}-x_{n+1}\right\|+\left\|x_{n+1}-y_{n}\right\| \rightarrow 0 \quad(\text { as } n \rightarrow \infty) .
$$

Step 5. We show that $\lim _{n \rightarrow \infty}\left\|x_{n}-z_{n}\right\|=0$. By taking $x_{n}$ and $z_{n}$ instead of $x_{t}$ and $z_{t}$ in the proof of Proposition 3.3 (iv), respectively, the result follows from the proof of Proposition 3.3 (iv) together with Step 4. 
Step 6. We show that $\lim _{n \rightarrow \infty}\left\|x_{n}-u_{n}\right\|=0$, where $u_{n}=T_{r_{n}} z_{n}$. In fact, from (3.11) and Step 2, we have

$$
\left\|x_{n}-u_{n}\right\|=\left\|x_{n}-T_{r_{n}} z_{n}\right\| \leqslant\left\|x_{n}-x_{n+1}\right\|+\left\|x_{n+1}-T_{r_{n}} z_{n}\right\| \rightarrow 0 \quad(\text { as } n \rightarrow \infty) .
$$

Step 7. We show that $\lim _{n \rightarrow \infty}\left\|u_{n}-z_{n}\right\|=0$, where $u_{n}=T_{r_{n}} z_{n}$. In fact, from Step 5 and Step 6, we have

$$
\left\|u_{n}-z_{n}\right\| \leqslant\left\|u_{n}-x_{n}\right\|+\left\|x_{n}-z_{n}\right\| \rightarrow 0 \quad(\text { as } n \rightarrow \infty) .
$$

Step 8. We show that $\limsup _{n \rightarrow \infty}\left\langle(I-A) \widetilde{x}, x_{n}-\widetilde{x}\right\rangle \leqslant 0$. To this end, take a subsequence $\left\{x_{n_{k}}\right\}$ of $\left\{x_{n}\right\}$ such that

$$
\limsup _{n \rightarrow \infty}\left\langle(I-A) \widetilde{x}, x_{n}-\widetilde{x}\right\rangle=\lim _{k \rightarrow \infty}\left\langle(I-A) \widetilde{x}, x_{n_{k}}-\tilde{x}\right\rangle .
$$

Without loss of generality, we may assume that $x_{n_{k}} \rightarrow p$. Take $x_{n_{k}}$ and $z_{n_{k}}$ in place of $x_{t_{n}}$ and $z_{t_{n}}$ in Step 3 and Step 4 of proof of Theorem 3.4. Then, from Step 3 and Step 4 in proof of Theorem 3.4 along with Step 5 and Step 7, we derive $p \in \Omega \cap \operatorname{Fix}(T)$. Hence, from (3.4), we conclude

$$
\limsup _{n \rightarrow \infty}\left\langle(I-A) \widetilde{x}, x_{n}-\tilde{x}\right\rangle=\lim _{k \rightarrow \infty}\left\langle(I-A) \widetilde{x}, x_{n_{k}}-\tilde{x}\right\rangle=\langle(I-A) \widetilde{x}, p-\tilde{x}\rangle \leqslant 0 .
$$

Step 9. We show that $\lim _{n \rightarrow \infty}\left\|x_{n}-\widetilde{x}\right\|=0$. Note that $\widetilde{x} \in \Omega \cap \operatorname{Fix}(T)$. Let $z_{n}=R x_{n}$. By (3.10), $\widetilde{x}=R \widetilde{x}$, and $\tilde{x}=T_{r_{n}} \tilde{x}$, we deduce

$$
\begin{aligned}
y_{n}-\tilde{x} & =\left(I-\alpha_{n} \mu G\right) T_{r_{n}} R x_{n}-\left(I-\alpha_{n} \mu G\right) T_{r_{n}} R \widetilde{x}+\alpha_{n}\left(\gamma V x_{n}-\mu G \widetilde{x}\right) \\
& =\left(I-\alpha_{n} \mu G\right) T_{r_{n}} z_{n}-\left(I-\alpha_{n} \mu G\right) T_{r_{n}} \widetilde{x}+\alpha_{n}\left(\gamma V x_{n}-\mu G \widetilde{x}\right),
\end{aligned}
$$

and

$$
x_{n+1}-\tilde{x}=\left(I-\beta_{n} A\right)\left(T_{r_{n}} z_{n}-T_{r_{n}} \tilde{x}\right)+\beta_{n}\left(y_{n}-\tilde{x}\right)+\beta_{n}(I-A) \widetilde{x} .
$$

Applying Lemma 2.1, Lemma 2.5 and Lemma 2.6, we obtain

$$
\begin{aligned}
\left\|y_{n}-\tilde{x}\right\|^{2} & =\left\|\left(I-\mu \alpha_{n} G\right) T_{r_{n}} z_{n}-\left(I-\mu \alpha_{n} G\right) T_{r_{n}} \tilde{x}+\alpha_{n}\left(\gamma V x_{n}-\mu G \tilde{x}\right)\right\|^{2} \\
& \leqslant\left\|\left(I-\mu \alpha_{n} G\right) T_{r_{n}} z_{n}-\left(I-\mu \alpha_{n} G\right) T_{r_{n}} \tilde{x}\right\|^{2}+2 \alpha_{n}\left\langle\gamma V x_{n}-\mu G \tilde{x}, y_{n}-\tilde{x}\right\rangle \\
& \leqslant\left(1-\alpha_{n} \tau\right)^{2}\left\|x_{n}-\widetilde{x}\right\|^{2}+2 \alpha_{n}\left\|\gamma V x_{n}-\mu G \tilde{x}\right\|\left\|y_{n}-\widetilde{x}\right\| \\
& \leqslant\left\|x_{n}-\tilde{x}\right\|^{2}+2 \alpha_{n}\left\|\gamma V x_{n}-\mu G \tilde{x}\right\|\left\|y_{n}-\tilde{x}\right\|,
\end{aligned}
$$

and hence

$$
\begin{aligned}
\left\|x_{n+1}-\widetilde{x}\right\|^{2}= & \left\|\left(I-\beta_{n} A\right)\left(T_{r_{n}} z_{n}-T_{r_{n}} \widetilde{x}\right)+\beta_{n}\left(y_{n}-\widetilde{x}\right)+\beta_{n}(I-A) \widetilde{x}\right\|^{2} \\
\leqslant & \left\|\left(I-\beta_{n} A\right)\left(T_{r_{n}} z_{n}-T_{r_{n}} \widetilde{x}\right)\right\|^{2}+2 \beta_{n}\left\langle y_{n}-\widetilde{x}, x_{n+1}-\widetilde{x}\right\rangle+2 \beta_{n}\left\langle(I-A) \widetilde{x}, x_{n+1}-\widetilde{x}\right\rangle \\
\leqslant & \left(1-\beta_{n} \bar{\gamma}\right)^{2}\left\|z_{n}-\widetilde{x}\right\|^{2}+2 \beta_{n}\left\|y_{n}-\widetilde{x}\right\|\left\|x_{n+1}-\widetilde{x}\right\|+2 \beta_{n}\left\langle(I-A) \widetilde{x}, x_{n+1}-\widetilde{x}\right\rangle \\
\leqslant & \left(1-\beta_{n} \bar{\gamma}\right)^{2}\left\|x_{n}-\widetilde{x}\right\|^{2}+\beta_{n}\left(\left\|y_{n}-\widetilde{x}\right\|^{2}+\left\|x_{n+1}-\widetilde{x}\right\|^{2}\right)+2 \beta_{n}\left\langle(I-A) \widetilde{x}, x_{n+1}-\widetilde{x}\right\rangle \\
\leqslant & \left(1-\beta_{n} \bar{\gamma}\right)^{2}\left\|x_{n}-\widetilde{x}\right\|^{2}+\beta_{n}\left[\left\|x_{n}-\widetilde{x}\right\|^{2}+2 \alpha_{n}\left\|\gamma V x_{n}-\mu G \widetilde{x}\right\|\left\|y_{n}-\widetilde{x}\right\|\right] \\
& +\beta_{n}\left\|x_{n+1}-\widetilde{x}\right\|^{2}+2 \beta_{n}\left\langle(I-A) \widetilde{x}, x_{n+1}-\widetilde{x}\right\rangle \\
= & {\left[\left(1-\beta_{n} \bar{\gamma}\right)^{2}+\beta_{n}\right]\left\|x_{n}-\widetilde{x}\right\|^{2}+2 \alpha_{n} \beta_{n}\left\|\gamma V x_{n}-\mu F \widetilde{x}\right\|\left\|y_{n}-\widetilde{x}\right\| } \\
& +\beta_{n}\left\|x_{n+1}-\widetilde{x}\right\|^{2}+2 \beta_{n}\left\langle(I-A) \widetilde{x}, x_{n+1}-\widetilde{x}\right\rangle .
\end{aligned}
$$

It then follows from (3.20) that

$$
\begin{aligned}
\left\|x_{n+1}-\widetilde{x}\right\|^{2} \leqslant & \frac{\left(1-\beta_{n} \bar{\gamma}\right)^{2}+\beta_{n}}{1-\beta_{n}}\left\|x_{n}-\widetilde{x}\right\|^{2}+\frac{\beta_{n}}{1-\beta_{n}}\left[2 \alpha_{n}\left\|\gamma V x_{n}-\mu G \widetilde{x}\right\|\left\|y_{n}-\widetilde{x}\right\|+2\left\langle(I-A) \widetilde{x}, x_{n+1}-\widetilde{x}\right\rangle\right] \\
= & \left(1-\frac{2 \beta_{n}(\bar{\gamma}-1)}{1-\beta_{n}}\right)\left\|x_{n}-\widetilde{x}\right\|^{2} \\
& +\frac{2 \beta_{n}(\bar{\gamma}-1)}{1-\beta_{n}} \cdot \frac{1}{2(\bar{\gamma}-1)}\left[2 \alpha_{n}\left\|\gamma V x_{n}-\mu G \widetilde{x}\right\|\left\|y_{n}-\widetilde{x}\right\|+\beta_{n} \bar{\gamma}^{2}\left\|x_{n}-\widetilde{x}\right\|^{2}\right. \\
& \left.+2\left\langle(A-I) \widetilde{x}, \widetilde{x}-x_{n+1}\right\rangle\right] \\
\leqslant & \left(1-\omega_{n}\right)\left\|x_{n}-\widetilde{x}\right\|^{2}+\omega_{n} \delta_{n},
\end{aligned}
$$


where

$$
\omega_{n}=\frac{2 \beta_{n}(\bar{\gamma}-1)}{1-\beta_{n}} \text { and } \delta_{n}=\frac{1}{2(\bar{\gamma}-1)}\left[2 \alpha_{n} M_{4}++\beta_{n} \bar{\gamma}^{2} M_{5}+2\left\langle(A-I) \widetilde{x}, \widetilde{x}-x_{n+1}\right\rangle\right],
$$

where $M_{4}=\sup \left\{\left\|\gamma \vee x_{n}-\mu G \widetilde{x}\right\|\left\|y_{n}-\widetilde{x}\right\|: n \geqslant 0\right\}$ and $M_{5}=\sup \left\{\left\|x_{n}-\widetilde{x}\right\|^{2}: \geqslant 0\right\}$. It can be easily seen from conditions (C1) and (C2), and Step 8 that $\omega_{n} \rightarrow 0, \sum_{n=0}^{\infty} \omega_{n}=\infty$ and $\limsup _{n \rightarrow \infty} \delta_{n} \leqslant 0$. From Lemma 2.2 with $v_{n}=0$, we conclude that $\lim _{n \rightarrow \infty}\left\|x_{n}-\widetilde{x}\right\|=0$. This completes the proof.

Taking $\mathrm{G} \equiv \mathrm{I}, \mu=1$, and $\gamma=1$ in Theorem 3.7, we obtain the following corollary.

Corollary 3.8. Let $\left\{x_{n}\right\}$ be generated by the following iterative algorithm:

$$
\left\{\begin{array}{l}
y_{n}=\alpha_{n} V x_{n}+\left(1-\alpha_{n}\right) T_{r_{n}} R x_{n}, \\
x_{n+1}=\left(I-\beta_{n} A\right) T_{r_{n}} R x_{n}+\beta_{n} y_{n}, \quad \forall n \geqslant 0 .
\end{array}\right.
$$

Assume that the sequences $\left\{\alpha_{n}\right\},\left\{\beta_{n}\right\}$, and $\left\{r_{n}\right\}$ satisfy the conditions (C1)-(C4) in Theorem 3.7. Then $\left\{x_{n}\right\}$ converges strongly to $\tilde{x} \in \Omega \cap \mathrm{Fix}(\mathrm{T})$, which is the unique solution of the variational inequality (3.4).

Taking $\mathrm{T} \equiv \mathrm{I}, \mathrm{G} \equiv \mathrm{I}, \mu=1$ and $\gamma=1$ in Theorem 3.7, we have the following corollary.

Corollary 3.9. Let $\left\{x_{n}\right\}$ be generated by the following iterative algorithm:

$$
\left\{\begin{array}{l}
y_{n}=\alpha_{n} V x_{n}+\left(1-\alpha_{n}\right) R x_{n}, \\
x_{n+1}=\left(I-\beta_{n} A\right) R x_{n}+\beta_{n} y_{n}, \quad \forall n \geqslant 0 .
\end{array}\right.
$$

Assume that the sequences $\left\{\alpha_{n}\right\}$ and $\left\{\beta_{n}\right\}$ satisfy the conditions (C1)-(C3) in Theorem 3.7. Then $\left\{x_{n}\right\}$ converges strongly to $\widetilde{x} \in \Omega$, which is the unique solution of the variational inequality (3.9).

Taking $F_{1}=F_{2}=F, \lambda=v$ and $x^{*}=y^{*}$ in GSVI (1.3), we have the following result.

Corollary 3.10. Let $\left\{x_{n}\right\}$ be generated by the following iterative algorithm:

$$
\left\{\begin{array}{l}
y_{n}=\alpha_{n} \gamma V x_{n}+\left(I-\alpha_{n} \mu G\right) T_{r_{n}} F_{\lambda} x_{n}, \\
x_{n+1}=\left(I-\beta_{n} A\right) T_{r_{n}} F_{\lambda} x_{n}+\beta_{n} y_{n}, \quad \forall n \geqslant 0 .
\end{array}\right.
$$

Assume that the sequences $\left\{\alpha_{n}\right\},\left\{\beta_{n}\right\}$, and $\left\{r_{n}\right\}$ satisfy the conditions (C1)-(C4) in Theorem 3.7. Then $\left\{x_{n}\right\}$ converges strongly to $\widetilde{x} \in \mathrm{VI}(\mathrm{C}, \mathrm{F}) \cap \mathrm{Fix}(\mathrm{T})$, which is the unique solution of the variational inequality

$$
\langle(A-I) \widetilde{x}, \widetilde{x}-p\rangle \leqslant 0, \quad \forall p \in V I(C, F) \cap \operatorname{Fix}(T) .
$$

Proof. If $F_{1}=F_{2}=F, \lambda=v$ and $x^{*}=y^{*}$ in GSVI (1.3), then GSVI (1.3) reduces to the classical variational inequality problem VIP (1.1) for a continuous monotone mapping $F$ and $R x=F_{\lambda} x$ in Proposition 3.1. Thus the result follows from Theorem 3.7.

Remark 3.11.

1) The $\tilde{x} \in \Omega \cap \operatorname{Fix}(T)$ in our results is the unique solution of minimization problem

$$
\min _{x \in D} \frac{1}{2}\langle(A-I) x, x\rangle,
$$

where the constraint set $D$ is $\Omega \cap \operatorname{Fix}(T)$. In fact, the variational inequality (3.4) is the optimality condition for the minimization problem (3.21). Thus, for finding an element of $\Omega \cap$ Fix $(T)$, where $T$ is a continuous pseudocontractive mapping, and $F_{1}$ and $F_{2}$ are continuous monotone mappings, Theorem 3.4, Corollary 3.5, Theorem 3.7 and Corollary 3.8 are new ones different from previous those introduced by some authors (for example, see [1, 2]). 
2) Corollary 3.6 and Corollary 3.9 are also new results for finding an element of $\Omega$, where $F_{1}$ and $F_{2}$ are continuous monotone mappings.

3) Using the same method as in [18], we can replace $F_{\lambda}$ by $F_{r_{n}}$ in Corollary 3.10 along with the condition (C4) on $\left\{r_{n}\right\}$. In this case, Corollary 3.10 is a new one, which improves, supplements and develops [14, Theorem 3.1] and Theorem 3.1 of Zegeye and Shahzad [18] in the following aspects:

(a) The $\rho$-Lipschitzian and $\eta$-strongly monotone mapping $G$ with constants $\rho, \eta>0$ is used to develop our iterative method by virtue of Yamada's hybrid steepest-descent method [16].

(b) The contractive mapping $f$ with constant $\xi \in(0,1)$ in $[14,18]$ is extended to the case of a Lipschitzian mapping $\mathrm{V}$ with constant $l \geqslant 0$.

(c) The strongly positive linear bounded self-adjoint operator $A$ is used to consider the minimization problem (3.21) whose the constraint set $D$ is $V I(C, F) \cap$ Fix $(T)$.

4) For finding an element of $\mathrm{VI}(\mathrm{C}, \mathrm{F}) \cap \mathrm{Fix}(\mathrm{T})$, Corollary 3.10 also improves, supplements and develops the corresponding results of $[3,5,7,13]$ in the following aspects together with (a), (b) and (c) in 3):

(1) The inverse-strongly monotone mapping $F$ in $[3,5,7,13]$ is extended to the case of the continuous monotone mapping $\mathrm{F}$.

(2) The nonexpansive mapping $S$ in $[3,5,13]$ or the strictly pseudocontractive mapping $T$ in [7] is extended to the case of a continuous pseudocontractive mapping $\mathrm{T}$.

\section{Acknowledgment}

This study was supported by research funds from Dong-A University.

The author would like to thank the anonymous reviewers for their valuable suggestions and comments.

\section{References}

[1] A. S. M. Alofi, A. Latif, A. E. Al-Marzooei, J. C. Yao, Composite viscosity iterative methods for general systems of variational inequalities and fixed point problem in Hilbert spaces, J. Nonlinear Convex Anal., 17 (2016), 669-682. 1, 3, 3.11

[2] L.-C. Ceng, C.-Y. Wang, J.-C. Yao, Strong convergence theorems by a relaxed extragradient method for a general system of variational inequalities, Math. Methods Oper. Res., 67 (2008), 375-390. 1, 1, 3.11

[3] J.-M. Chen, L.-J. Zhang, T.-G. Fan, Viscosity approximation methods for nonexpansive mappings and monotone mappings, J. Math. Anal. Appl., 334 (2007), 1450-1461. 1, 3.11

[4] K. Goebel, W. A. Kirk, Topics in metric fixed point theory, Cambridge Studies in Advanced Mathematics, Cambridge University Press, Cambridge, (1990). 2.3

[5] H. Iiduka, W. Takahashi, Strong convergence theorems for nonexpansive mappings and inverse-strongly monotone mappings, Nonlinear Anal., 61 (2005), 341-350. 1, 1, 3.11

[6] J. S. Jung, A general composite iterative method for strictly pseudocontractive mappings in Hilbert spaces, Fixed Point Theory Appl., 2014 (2014), 21 pages. 1, 1, 3, 3

[7] J. S. Jung, A composite extragradient-like algorithm for inverse-strongly monotone mappings and strictly pseudocontractive mappings, Linear Nonlinear Anal., 1 (2015), 271-285. 1, 3.11

[8] G. M. Korpelevič, An extragradient method for finding saddle points and for other problems, (Russian) Ékonom. i Mat. Metody, 12 (1976), 747-756. 1

[9] P.-L. Lions, G. Stampacchia, Variational inequalities, Comm. Pure Appl. Math., 20 (1967), 493-519. 1

[10] F.-S. Liu, M. Z. Nashed, Regularization of nonlinear ill-posed variational inequalities and convergence rates, Set-Valued Anal., 6 (1998), 313-344. 1, 1

[11] G. Marino, H.-K. Xu, A general iterative method for nonexpansive mappings in Hilbert spaces, J. Math. Anal. Appl., 318 (2006), 43-52. 2.4, 2.5

[12] G. J. Minty, On the generalization of a direct method of the calculus of variations, Bull. Amer. Math. Soc., 73 (1967), 315-321. 3

[13] W. Takahashi, M. Toyoda, Weak convergence theorems for nonexpansive mappings and monotone mappings, J. Optim. Theory Appl., 118 (2003), 417-428. 1, 3.11 
[14] Y. Tang, Strong convergence of viscosity approximation methods for the fixed-point of pseudo-contractive and monotone mappings, Fixed Point Theory Appl., 2013 (2003), 11 pages. 1, 3.11

[15] H.-K. Xu, Iterative algorithms for nonlinear operators, J. London Math. Soc., 66 (2002), 240-256. 2.2

[16] I. Yamada, The hybrid steepest descent method for the variational inequality problem over the intersection of fixed point sets of nonexpansive mappings, Inherently parallel algorithms in feasibility and optimization and their applications, Haifa, (2000), Stud. Comput. Math., North-Holland, Amsterdam, 8 (2001), 473-504. 1, 2, 3.11

[17] H. Zegeye, An iterative approximation method for a common fixed point of two pseudocontractive mappings, ISRN Math. Anal., 2011 (2011), 14 pages. 2, 2.7, 2.8

[18] H. Zegeye, N. Shahzad, Strong convergence of an iterative method for pseudo-contractive and monotone mappings, J. Global Optim., 54 (2012), 173-184. 1, 3, 3.11 